\title{
Los libros, a las fábricas, galardonada con el Premio Nacional de Fomento de la Lectura 2021
}

URÍA FERNÁNDEZ

Centro Documental Fundación Anastasio de Gracia

La iniciativa de fomento de la lectura Los libros, a las fábricas, creada en 2014 por la Fundación Anastasio de Gracia, para incentivar el hábito lector entre los trabajadores de la industria española, ha sido reconocida con el Premio Nacional de Fomento de la Lectura 2021. Tras siete años, en el proyecto han participado 6300 trabajadores de 63 plantas de producción de todo el país. Arranca ahora su octava edición, dedicada al género de la novela negra, bajo el eslogan ¡Leer no es un crimen!

Fundación Anastasio de Gracia, fomento de la lectura, Los libros, a las fábricas

\section{Un proyecto que sale a la búsqueda de nuevos lectores}

La iniciativa de fomento de la lectura titulada Los libros, a las fábricas, nació como respuesta a los altos índices de absentismo lector de nuestro país, donde aproximadamente un $40 \%$ de la población manifiesta no leer nunca. Su fin principal es promover el gusto por la lectura en el ámbito laboral, pues es el lugar donde la población adulta desarrolla un tercio de su vida, alejada de estímulos que le inviten a sumergirse en el mundo de los libros.

El proyecto arrancó en 2014, cuando el Centro Documental de la Fundación Anastasio de Gracia puso en marcha un proyecto piloto en el sector de automóvil titulado Autores y autos ¡Arráncate a leer! Para su implantación, contó con la colaboración de las secretarías de Política Social e Igualdad y del sector de Automoción de la Federación del Metal, Construcción y Afines de Unión General de Trabajadores (MCA-UGT). Nacía así un espacio de encuentro entre el mundo de la Cultura y del Trabajo en torno a los libros.

La gran acogida que tuvo la experiencia entre todos los actores implicados - trabajadores, empresarios, escritores y editoriales-, así como la solicitud de nuevas empresas para que la actividad se expandiera a otros ámbitos productivos, impulsó el crecimiento del proyecto en años sucesivos, cambiando su denominación original por la de Los libros, a las fábricas, a partir de 2015. En su segunda edición, la iniciativa sumó a su campo de actuación a las empresas siderúrgicas y de construcción. Y tras ellas, año a año, se han ido incorporando nuevos sectores, como el energético, el químico, el textil y el agro.

Tras siete años, la amplia implantación del proyecto a lo largo y ancho de todo el Estado, motivó que, el pasado mes de junio, el jurado del Premio Nacional de Fomento de la Lectura 
correspondiente al año 2021 decidiera conceder dicho galardón a la Fundación Anastasio de Gracia. Según el fallo emitido por el jurado, Los libros, a las fábricas ha sido merecedora del reconocimiento por:

Tratarse de un proyecto transversal, globalizador y con un sentido social, que se dirige a sectores de la población tradicionalmente poco atendidos en el ámbito de fomento de la lectura.

Junto a la Fundación Anastasio de Gracia, también ha resultado galardonada en esta edición la revista literaria Litoral, por tratarse de una de las cabeceras de mayor prestigio dentro de los movimiento y literarios y artísticos del mundo hispánico.

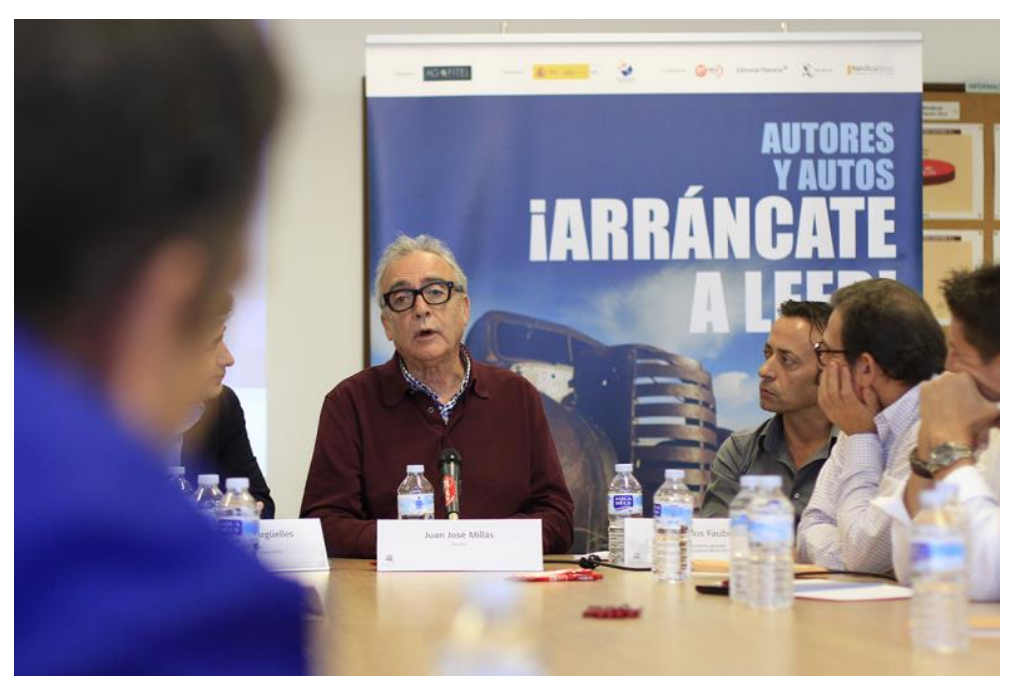

El escritor Juan José Millás inauguró en 2014 el proyecto piloto titulado Autores y autos ¡Arráncate a leer! en la planta de Ford, en el municipio valenciano de Almusafes.

\section{Los objetivos}

La misión de Los libros, a las fábricas es implicar a empresarios y trabajadores en la consecución de un fin común: el progreso del país depende de que la población lea más; entendiendo como progreso el avance en los aspectos ético, social, cultural y político.

Para lograr dicho fin se marcaron cinco objetivos:

- Incluir el fomento de la lectura -y por extensión de los valores culturales-como parte fundamental de la responsabilidad social corporativa de las empresas.

- Formar líderes laborales en el ámbito de la promoción de la lectura.

- Crear conciencia lectora induciendo a las personas a reflexionar sobre lo que piensa, dice y hace acerca de la lectura, buscando congruencia entre estos tres actos.

- Lograr que los trabajadores establezcan a corto y mediano plazo proyectos personales y familiares de lectura.

- Establecer la idea de que en sociedades en donde no se lee todos debemos ser promotores de la lectura desde los ámbitos en que nos movamos. 


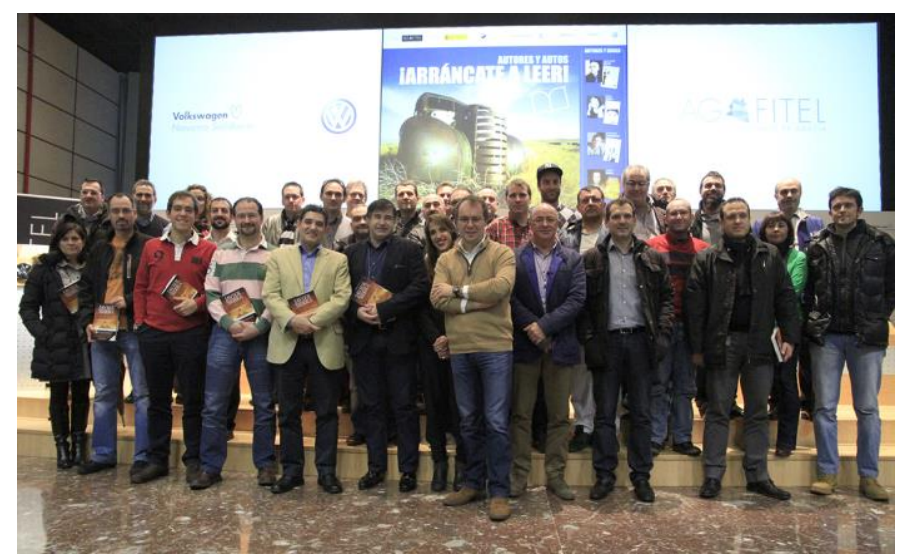

Los trabajadores de Volkswagen (Pamplona, Navarra) disfrutaron del encuentro con Javier Sierra y su libro La pirámide inmortal, en 2014.

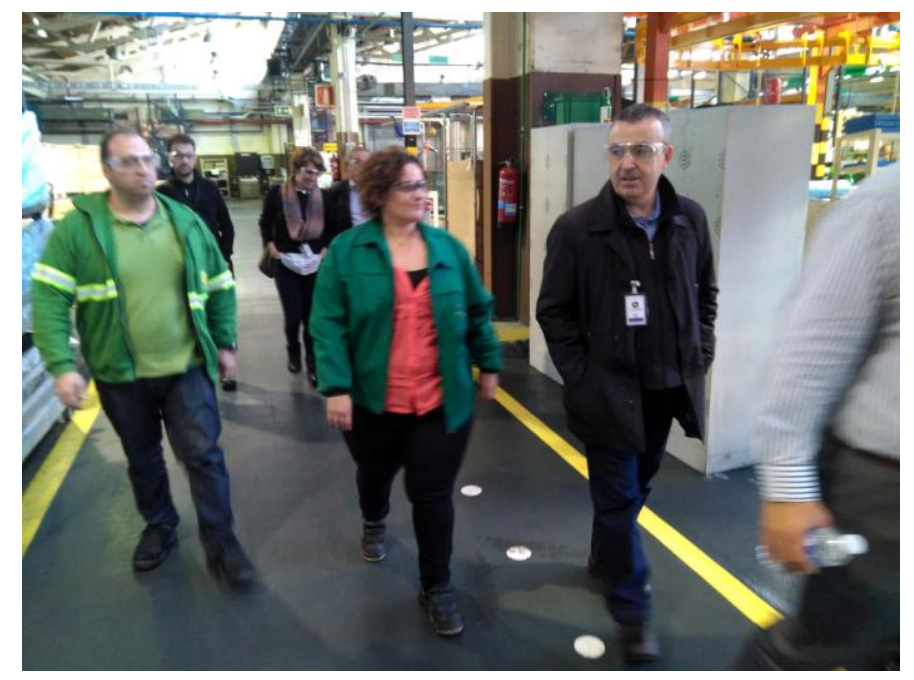

Lorenzo Silva visita la fábrica de John Deere (Getafe, Madrid) tras el coloquio con los trabajadores sobre su libro La niebla y la doncella.

\section{La dinámica del proyecto}

En cada centro laboral, todo comienza invitando a los trabajadores a que participen en la actividad. Durante quince días se desarrolla una campaña de animación lectora en la que se distribuyen carteles y trípticos por las fábricas, con toda la información sobre la actividad. Para esta labor de difusión se cuenta con colaboración de las secciones sindicales de la Federación de Industria Construcción y Agro de UGT y de los departamentos de recursos humanos de las empresas.

Para participar, los trabajadores sólo tienen que rellenar una inscripción, a cambio de la cual se les entrega gratuitamente el libro escogido para su fábrica. En cada factoría pueden participar un máximo de cien trabajadores. Una vez el libro está en manos de todos los lectores de la fábrica, tienen un mes de plazo para leerlo con calma. Al término de este periodo, se celebra 
el encuentro con el autor del libro en las mismas dependencias de la empresa, durante el que intercambian sus opiniones e inquietudes en torno a la obra leída.

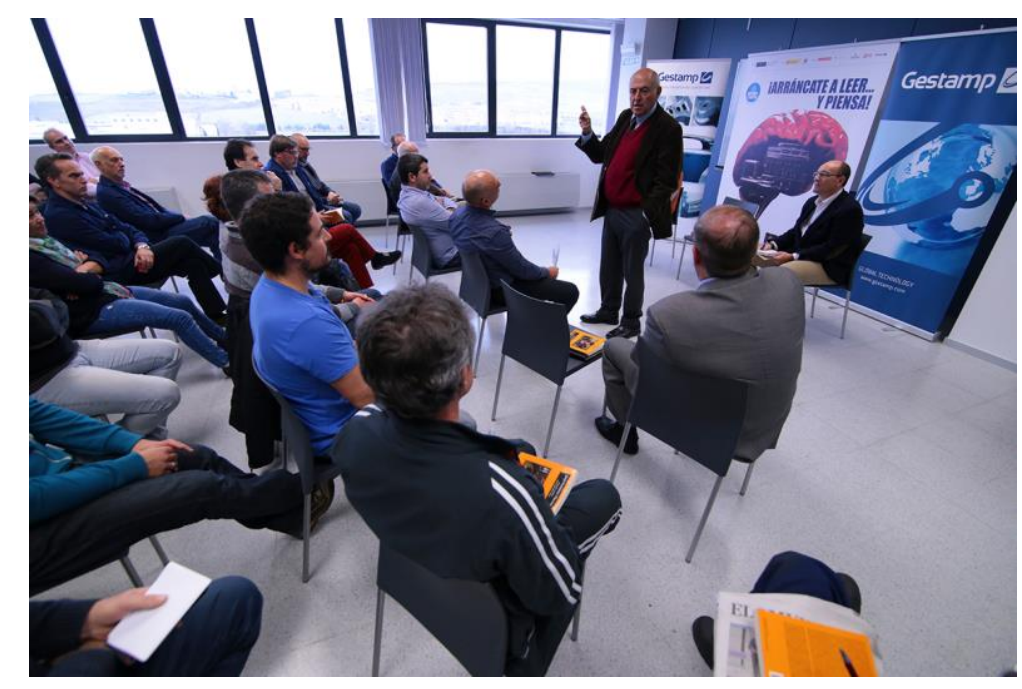

En 2015, el filósofo José Antonio Marina compartió con los trabajadores de Gestamp (Navarra) la lectura de su libro Pequeño tratado de los grandes vicios.

\section{En la variedad está el gusto}

A lo largo de sus siete ediciones, Los libros, a las fábricas ha ido evolucionando y cambiando los contenidos y géneros abordados en cada una de ellas. Atendiendo al refrán popular de «renovarse o morir», hasta ahora los trabajadores de las factorías participantes han podido disfrutar de temáticas tan diferentes como la filosofía, la poesía, la novela erótica, la novela gráfica o la novela histórica.

La octava edición, dedicada a la novela negra, arrancó el 11 de noviembre, en la factoría de Nissan, en Ávila. El escritor Lorenzo Silva (que participa por segunda vez en el proyecto) se encargó de inaugurarla compartiendo su novela Nadie vale más que otro con los lectores de la factoría del motor abulense.

\section{Un paso más allá}

Los profesionales de Centro Documental de la Fundación Anastasio de Gracia están trabajando en un nuevo modelo de actividad que permita dar continuidad a los clubes de lectura en aquellas fábricas que ya han participado en el proyecto matriz. Bajo la denominación Lectulabora, surgirá una red formal de lectores entre las empresas involucradas hasta la fecha en Los libros, a las fábricas. Se trata de ir un paso más allá, que permita a los trabajadores organizarse autónomamente en cada centro en torno a los libros. 
Sobre el autor

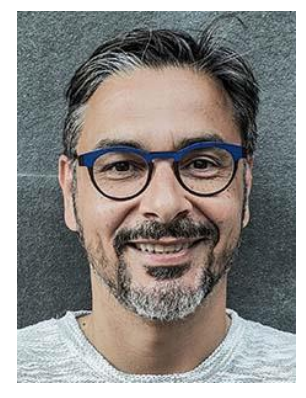

URÍA FERNÁNDEZ

Director - Área de Cultura y Centro Documental Fundación Anastasio de Gracia

Doctor en Ciencias de la Información, es miembro de la junta directiva de SEDIC y coordinador de la Plataforma \#SalvaPeironcely10. Asimismo, coodirige el Festival Robert Capa estuvo aquí y es el creador y coordinador de la iniciativa de fomento de la lectura Los libros, a las fábricas.

- jmuria@agfitel.es

- https://www.linkedin.com/in/ur\%C3\%ADa-fern\%C3\%A1ndez5b9b695b/ 